\title{
The Direction of Subjects-Related Career Education by Developing Teachers' Training Program Reflecting Journey Map: Focused on the Application of Design Thinking Process
}

\section{여정 지도를 통한 교과연계 진로교육 교사 연수 프로그램 설계: 디자인 사고 프로세스 적용을 중심으로}

Yi Seul Jung ${ }^{1}$, Eun Jeung Kim²

$$
\text { 정이슬 } 1 \text {, 김은정 } 2
$$

${ }^{1}$ Student, Arts \& Cultural Management Department, Hongik University, South Korea, white2718@gmail.com

${ }^{2}$ Professor, Department of Home Economics Education, Kyungpook National University, South Korea, coronia3@knu.ac.kr

Corresponding author: Eun Jeung Kim

\begin{abstract}
The purpose of this study is to suggest the direction of subjects-related career education by developing teachers' training program that applies the design thinking process reflecting the journey map. Through this study, the necessity of career education training and the level of detailed requirements recognized through the experiences of secondary school teachers were confirmed. Furthermore, the necessity of presenting a teaching and learning methodology that can be applied and spread to various subjects was verified. The journey map was prepared and analyzed as a method to examine the necessity of career education training for teachers and find solutions. As a result of the study, a design thinking process application training program was developed, and a framework of a highly effective teaching model that can be applied to actual subject-related career lessons was presented. Through the presentation of such training programs, teaching and learning methods, it was possible to promote the composition and implementation of diverse youth career education based on the subject expertise of teachers. In the entire process of developing a design thinking application training program that reflects youth career education competency, teachers were able to experience creative problem-solving on their own and improve career education-related competencies through contextual understanding.
\end{abstract}

Keywords: Subjects-related Career Education, Teacher Training Program, Journey Map, Design Thinking Process

요약: 본 연구는 여정 지도를 반영한 디자인 사고 프로세스를 적용한 일반교사 연수 프로그램을 개발하여 교과 연계 진로교육의 방향을 제시하는데 목적이 있다. 본 연구를 통해 중등학교 교사들의 경험을 통해 인식하고 있는 진로교육 연수의 필요성과 세부적인 요구 수준을 확인하고, 다양한 교과에 적용 및 확산이 가능한 교수학습 방법론 제시의 필요성을 확인하였다. 일반교사 대상 진로교육 연수의 필요성 고찰 및 해결 방안 발견을 위한 방법으로 여정지도의 작성 및 분석을 진행하였다. 연구의 결과로 디자인 사고 프로세스 적용 연수

Received: August 14, 2021; 1st Review Result: September 30, 2021; 2nd Review Result: November 16, 2021 Accepted: December 31, 2021 
프로그램을 개발하여 실제 교과연계 진로수업에 적용할 수 있는 실효성 높은 수업 모형의 틀을 제시하였다. 이와 같은 연수 프로그램 및 교수학습 방안은 교사들의 교과 전문성을 토대로 한 다각적인 청소년 진로교육의 구성에 직접적인 활용이 가능하여, 현장에서의 교과 연계 진로교육 시행 및 확산을 촉진할 수 있다. 본 연구는 청소년 진로교육 역량을 반영한 디자인 사고 적용 연수 프로그램을 개발하는 전 과정에 사용자(user)로서 현직 교사들의 참여를 통해 그들의 아이디어를 검증함으로써, 본 설계 프로그램을 통한 교사들의 창의적 문제해결 과정 경험 및 이해, 진로교육 관련 역량 향상의 가능성을 확인할 수 있었다.

핵심어: 교과 연계 진로교육, 교사 연수 프로그램, 여정 지도, 디자인 사고 프로세스

\section{1. 서론}

과학기술의 발달과 4차 산업혁명은 사회 패러다임의 급격한 전환과 함께, 인간의 생애주기에도 변화를 가져와 이전 세대와 다른 새로운 형태의 직업군이 등장하게 되었다. 최근 코로나19(COVID-19)로 인한 팬데믹(pandemic) 현상은 이러한 변화를 더욱 가속화시키는 요인으로, 공공 교육기관인 학교에서는 이에 대처할 수 있는 미래지향적인 진로교육에 대한 요구가 높아지고 있다. 그러나 근래까지도 학교에서의 진로교육은 전형적인 직업 선택 모델 중심의 프로그램으로 진행되고 있어 변화하는 사회에 대처할 수 있는 생애 설계 중심의 진로교육 시행이 필요하다. 특히, 미래 세대에는 주요 인재 역량으로 기술적 능력, 인지적 능력, 창의적 능력, 복합적 문제해결 능력, 콘텐츠 능력 등이 강조되므로, 이 역량들을 강화하기 위한 방안으로써 심층학습(deep-learning) 중심의 교과연계 진로교육 프로그램을 개발 및 실행하는 것이 요구된다[1].

중등교육 단계에서 진로교육의 경험이 학생에 미치는 영향력을 고려하였을 때, 더욱 체계적이고 실질적인 진로교육 프로그램 개발과 진행이 필요하다[2]. 현재, 중학교에서는 진로전담 교사를 통한 진로교육이 진행되고 있다. 그러나, 학교 현장에서는 담임 및 일반교사에 의한 진로교육과 지도가 높은 비중을 차지하고 있으며, 학생 및 학부모의 요구를 분석하였을 때 교과와 연계한 진로교육 및 진로경험의 제공이 더욱 중요한 실정이다[3]. 그럼에도 불구하고 대다수의 학교에서는 교과 수업 과정과 진로교육 연계의 중요성을 배제하고 있으며[4], 교과연계 진로교육의 내용도 실제적 역량을 키울 수 있는 활동이 아닌 직업소개나 탐색을 중심으로 구성되어 있다[3].

이는 담임 및 일반교사들의 단선적인 경력으로 인해 학생들에게 진취적인 진로역량 및 방향성을 제시하는데 한계가 있음을 보여준다. 따라서 창의성, 협업, 리더십 등 미래인재 역량과 학생의 진로 개발을 위해 일반교사의 진로교육 교육역량 강화가 무엇보다 필요할 것이다[4]. 그러나 현재 일반교사 대상의 진로교육 연수는 거의 시행되지 않고 있으며, 각 교과의 전문성을 기반으로 한 진로 교육 프로그램은 거의 이루어지고 있지 않은 상황이다. 교육청 등을 통해 배포되는 진로교육 자료가 배포되고 있으나 단순 진로 진학 지도에 초점이 맞춰 있거나 직업 구분에 기반한 내용으로 구성되어 있어, 일반교사들이 전문성을 갖고 실제 교육적 의미와 효과가 있는 진로 교육을 진행하기 한계점이 있다. 이에 일반교사 및 교과 연계를 위한 다양한 진로교육 연수 및 프로그램 지원을 통해 진로 교육에 대한 일반교사들의 전문성 함양을 촉진할 필요가 있다. 따라서 본 연구는 여정지도를 반영한 디자인 사고 프로세스를 적용한 일반교사 연수 프로그램을 개발하여 
교과 연계 진로교육의 방향을 제시하는데 목적이 있다. 이를 위해 일반교사들의 진로교육 관련 경험을 가장 잘 분석할 수 있는 여정 지도를 작성하고, 이를 바탕으로 한 교사 연수 프로그램을 개발하여 제시하고자 한다. 이 연구를 통해 다양한 교과를 통해 다양하고 확장적인 진로교육 활동이 학교 교육 현장에서 시행될 수 있도록 하고자 한다.

\section{2. 이론적 고찰}

\section{1 중등학교 교과연계 진로교육 필요성}

진로(career)는 일생을 통해 하는 일의 총체를 의미하며, 일생동안 개인이 소속된 모든 사회 단위에서 이루어지는 교육 활동을 진로교육(Career education)이라고 한다. 우리나라의 진로교육은 1985 년 한국교육개발원의 연구 보고서에서 '개인이 자신의 진로 계획 및 준비, 진로 선택, 선택한 진로에서 지속적으로 발전해 나가도록 돕는 과정'으로 정의하면서 교육의 토대를 마련하였다. 이후 한국진로교육학회에서는 진로교육을 '생산적인 사회 구성원, 행복한 개인으로서 삶을 영위할 수 있도록 돕는 교육' 으로 재정의하였다. 특히 진로교육의 확대는 2013년부터 시작된 자유학기제를 추진하기 위해 각 중학교에 진로를 담당하는 교사가 배치되면서 이루어졌다[5]. 진로전담 교사에게는 '진로와 직업' 교과와 자유 학기 전체적인 진로교육을 담당하는 역할이 주어졌다.

더욱이 2020년 자유 학년제의 전면 시행과 초등 및 고등학교 내의 진로전담 교사 배치 등은 진로교육의 중요성이 높아지는 상황을 보여준다[6]. 반면, 현재 학교에서의 진로교육은 진학, 직업소개나 탐색 활동 위주가 주를 이루고 있는데, 이는 전체 학생의 진로교육을 진로교사 1 인이 담당하는 것의 한계를 보여준다.

따라서 내실 있는 진로교육을 위해서는 일반교사들의 교과 수업 과정에서 교과와 진로교육을 연계할 필요가 있다. 이는 중 - 고등학생의 경우 진로교사보다 담임 및 교과 담당 교사와의 교류가 활발하고, 교과 수업을 통해 자연스럽게 진로와 연계한 수업이 이루어질 수 있는 상황에서 진로교육에서 일반교사의 역할이 중요하다고 할 것이다. 실제 2019년 진로교육 현황조사에 따르면 학생들은 일반교사를 통한 진로교육 및 교과 수업에 진로교육의 성취기준을 연계하여 운영하는[7] 교과연계 진로교육에 대한 요구가 높은 것으로 나타났다[4]. 그럼에도 불구하고 진로교사들을 위한 진로교육 연수에 비해 일반교사를 대상으로 한 진로교육 연수는 그 필요성이나 요구에 비해 턱없이 부족한 상황이다.

따라서 본 연구는 일반 교과 교사의 진로교육의 필요성을 연계한 수업의 필요성과 교과 교육과정 내에 진로교육 요소를 보다 내실화하기 위한 교사들의 요구에 초점[8]을 두고, 교과연계 진로교육을 위한 교사 연수 프로그램 설계 방안에 대해 탐색하고자 한다.

\section{2 디자인 사고(Design Thinking) 기반 학습의 특성 및 의의}

미래사회에서 중요하게 요구되는 개인의 역량은 다차원적 문제해결 능력, 비판적 사고의 의사결정 능력, 창의적 소통 능력 등 여러 분야에 대한 융·복합적 이해를 바탕으로 다양한 사회변화에 대응 및 생존할 수 있는 것이다. 이러한 사회적 요구는 청소년 교육의 초점이 단편적인 지식이나 능력 향상이 아닌, 개인의 역량과 인성 영역에 대한 전반적인 성장을 목표로 하고 미래지향적 관점에서 진행되어야 함을 시사한다. 특히, 4 차 산업혁명의 가속화는 이와 같은 교육의 중요성과 체계적 교육 방안 마련의 
필요성을 더욱 강조하고 있다. 이에 따라 선진 여러 나라들은 개인의 삶을 잘 영위하기 위해서는 인지적 측면뿐 아니라 사회정서 학습 기술(social and emotional learning skills, $\mathrm{SEL}$ )이 중요하며[9] 청소년이 자기 주도적으로 삶을 영위하도록 하기 위한 신념, 가치와 태도를 형성할 수 있는 역량 교육으로 정의되는 앙트러프러너십(Entrepreneurship) 교육 등의 맥락으로 학교 교육 방향을 재설정하고 있다[10]. 이러한 학교 교육의 미래 핵심 역량을 개발하기 위한 방법론으로서 다양한 학문과 영역, 조직에 적용되어 사회변화의 문제들을 실증적이고 창의적으로 해결하는 방안으로서 그 효과에 대해 검증된 디자인 사고(design thinking)가 다시 주목받고 있다[11].

디자인 사고는 창의적인 문제 해결을 이끌어 내는 통합적 교수학습 방법론으로서 자기 주도적 학습 환경을 마련하고, 학습자의 공감각적 이해 능력과 체계적 정보처리 능력, 창의적 사고 능력, 협력적 의사소통 능력 등을 강화한다는 점에서 미래 인재에 요구되는 역량 교육과 높은 연결성을 갖는다[12]. 또한, 학제적 특성의 학습모형들은 융합적 학습 방식의 교육을 체계적으로 진행할 수 있는 방법론으로 활용할 수 있다[13].

디자인 사고는 공감(Empathize), 정의(Define), 아이디어 도출(Ideate), 프로토타입(Prototype), 검증(Test)의 5단계로 설계된다[14]. 다른 프로젝트 기반 학습과 다르게 프로토타입, 검증과 같이 학습자의 지식 구성 과정에 참여자 간 소통 및 공감의 단계가 포함되어 있어, 문제 현상을 바라보는 새로운 관점과 이해를 통해 문제에 접근 및 해결한다는 특징이 있다[15].

최근 진로교육 분야에서는 자신의 삶에 대한 비전 및 가치 등을 탐색하고, 이러한 탐색 과정에서 진로에 대한 새로운 아이디어를 발견하게 하도록 하는 디자인 사고 프로세스를 프로그램에 적용하여 실효성 높은 교육적 효과를 이끌어내고 있다. 이는 자신의 성격이나 흥미를 기준으로 관련 분야를 탐색하고, 진로 목표를 설정하게 하던 기존의 진로교육 방법과 차이를 갖는 지점이다. 또한, 자신의 삶 전체를 이해하고 새로운 방향성 및 해결방안을 모색하게 한다는 점에서 다양한 환경 변화에 유연하게 적응 가능한 진로 역량을 개발할 수 있다[16].

무엇보다, 디자인 사고 프로세스의 특성은 우리나라 2015 개정 교육과정에서 중점적으로 제시되었던 주요 학습 역량과도 연결할 수 있으며[11], 교과교육에 적용할 경우 교육 목적과 학습 내용 등에 맞추어 변경 및 반복, 병행하여 사용이 가능하다는 특징이 있다[15]. 즉, 디자인 사고 프로세스 적용을 통해 교과연계 진로교육에 대한 다양한 프로그램 개발 및 융합적 교육 효과를 이끌어 낼 수 있으며, 학습자로 하여금 디자인 사고 기반 문제해결 과정을 통해 학문적 호기심 및 이해력 향상, 창의적 사고 및 표현 능력의 확장, 상호 협력적 대인관계 및 사회성 함양과 함께 각 개인의 내적 성장과 발전, 개선 등의 효과를 얻을 수 있다[11]. 따라서 각 교과에 적합한 적용과 심화된 교수학습 방법 설계를 위해, 교사들이 디자인 사고 프로세스에 대해 이해하고 교과연계 진로교육에 활용할 수 있는 교수학습 설계안이 필요하다. 따라서 본 연구에서는 교사들의 진로교육의 경험 과정을 여정 지도로 구성하여 분석하고, 더불어 교사가 적용할 수 있는 교과연계 진로교육 디자인 사고 프로세스 연수 설계안을 연구에 참여한 교사들의 활동을 중심으로 제안하고자 한다.

\section{3. 교과연계 진로교육 교사 여정지도}

\section{1 교과연계 진로교육 교사 여정 지도 구성}


여정지도(journey map)는 일련의 흐름 안에서 사용자 경험에 대한 다양한 정보를 통합적으로 수집 및 도식화하고, 이를 분석한 내용을 바탕으로 문제 상황에 대한 핵심적 이해와 문제해결 방안을 이끌어내는 정보 분석 방법이다. 사용자가 서비스 접점(touch point) 단계별로 격게 되는 경험들을 구체적으로 표현하여 보편적 척도만으로 측정이 어려운 여러 영향 요소들의 상관관계를 종합적으로 파악할 수 있으며, 각 접점 단계의 문제점을 발견하여 특정 상황에 효과적인 대안을 모색할 수 있다는 강점이 있다[17][18]. 또한, 사용자 의견을 반영한 상호작용적 개선 활동이 이루어질 수 있어, 사용자 경험의 과정들을 보다 전략적으로 발전시킬 수 있다[19]. 이러한 특성으로, 여정 지도는 다양한 분야의 사용자 경험 디자인을 위한 매우 유용한 수단으로서 적극 활용되고 있다. 본 연구에서는 여정지도를 통해 교과연계 진로교육에 대한 교사들의 경험 과정을 전체 맥락 및 세부 단계별로 설정하고, 실제 교육 현장의 문제 상황을 파악하고자 하였다. 이러한 사용자 중심의 직접적·집중적 방법을 적용함으로써 교사의 니즈(needs)와 선호에 맞는 교과연계 진로교육 교사 연수 프로그램 개발의 방향성을 발견할 수 있다고 보았다.

본 연구는 선행연구 고찰을 토대하여 '사용자 유형 이해', ‘사용자 경험 내용 조사', ‘조사 자료 분석 및 시각화’의 3 단계로 교과연계 진로교육 교사 여정 지도를 구성하였다. 각 단계에 따라 여정 지도의 구성요소인[17] 사용자 유형, 성취 목적, 경험 단계, 터치 포인트, 경험 데이터의 관계 흐름, 사용자 관점, 특이점, 외부요인 등이 정리되었다.

[표 1] 교과연계 진로교육 교사여정지도 구성을 위한 연구 절차

[Table 1] Research Process for Composing Subject-Related Career Education Teacher Journey Map

\begin{tabular}{|c|c|c|c|c|}
\hline \multirow{2}{*}{ 구분 } & \multicolumn{2}{|c|}{ 구성 방법 } & \multicolumn{2}{|c|}{ 실행 방법 } \\
\hline & 목표 내용 & 구성 요소 & 대상 & 실행 내용 \\
\hline $\begin{array}{l}\text { 선행 } \\
\text { 작업 } \\
\text { 단계 }\end{array}$ & $\begin{array}{l}\text { - 조사/분석 범위 } \\
\text { 설정 }\end{array}$ & $\begin{array}{l}\text { - 여정지도 작성 목적 } \\
\text { - 조사 대상자 선정 } \\
\text { - 타겟사용자 여정 } \\
\text { 정의 }\end{array}$ & $\begin{array}{l}\text { - 선행 연구 및 } \\
\text { 문헌 자료 }\end{array}$ & $\begin{array}{l}\text { - 데스크 리서치를 } \\
\text { 통한 인사이트 도출 } \\
\text { - 터치포인트 작성 }\end{array}$ \\
\hline $\begin{array}{l}\text { 연구 } \\
\text { 실행 } \\
\text { 단계 }\end{array}$ & $\begin{array}{l}\text { - 전체 여정 } \\
\text { 상호작용에 대한 } \\
\text { 고객 정보 수집 } \\
\text { - 여정지도 가설 설정 }\end{array}$ & $\begin{array}{l}\text { - 사용자 니즈/ } \\
\text { 인식/유형 } \\
\text { - 터치포인트 } \\
\text { 경험/만족 여부/ } \\
\text { 불만/건의 사항 등 } \\
\text { - 다양한 정보 취합 }\end{array}$ & $\begin{array}{l}\text { - } 1 \text { 차: 현직 } \\
\text { 중등학교 일반 } \\
\text { 교과 교사, 총 } \\
17 \text { 인 } \\
\text { - } 2 \text { 차: 현직 } \\
\text { 중등학교 } \\
\text { 일반교과 교사, } \\
\text { 총 } 7 \text { 인 }\end{array}$ & $\begin{array}{l}-1 \text { 차: 온라인 설문 조사, } \\
\text { 오프라인 FGI } \\
\text { - } 2 \text { 차: 관찰 조사, } \\
\text { 온라인 및 오프라인 } \\
\text { FGI(심층 인터뷰) }\end{array}$ \\
\hline $\begin{array}{l}\text { 여정지도 } \\
\text { 작성 } \\
\text { 단계 }\end{array}$ & $\begin{array}{l}\text { - 최종 여정 지도 } \\
\text { 작성 } \\
\text { - 시각화 }\end{array}$ & $\begin{array}{l}\text { - 여정에 따라 취합 } \\
\text { 정보 순차적 기술 } \\
\text { 및 분석 }\end{array}$ & - 수집 데이터 & $\begin{array}{l}\text { - 공감 기법을 통한 } \\
\text { 시각화 및 지도 작성 } \\
\text { - 사용자 여정, 요구 } \\
\text { 사항, 인식 등 구체화 }\end{array}$ \\
\hline
\end{tabular}

실효성 있는 여정 지도 구성을 위해서는 사용자 대상의 여정에 대한 구체적이고 실제적인 정보 수집이 중요하기에[20], 중등학교 현직 교사 중 진로 교과를 담당하지 않는 일반교사들을 연구 대상자로 선정하고 설문조사 및 관찰 조사, 심층 인터뷰 등을 
진행하였다. 교과연계 진로교육 교사 여정 지도 구성을 위한 각 단계별 구분과 방법, 실행 내용은 [표 1]과 같다. 이를 통해 일반교사들의 교과연계 진로교육 실행의 경험 과정을 통합적 맥락으로 이해하고, 현장에서 교사들이 느끼는 교수학습의 한계점을 기반으로 개선점을 도출하였다. 또, 참여 교사들의 추가 피드백 내용을 반영하여 실행 가능성 및 효과성 높은 문제해결 방법을 발견하는 교사 여정 지도를 작성할 수 있었다.

\section{2 교과연계 진로교육 교사 여정지도 분석}

본 연구자들은 위 3 단계의 연구 프로세스를 통해 중등학교 일반교사가 교과학습 활동 중 교실에서 진행하는 진로교육 경험 과정에 대한 교과연계 진로교육 교사 여정 지도를 [표 2]와 같이 구성할 수 있었다.

[표 2] 교과 연계 진로교육 교사 여정 지도

[Table 2] Subject-Related Career Education Teacher Journey Map

\begin{tabular}{|c|c|c|c|c|c|}
\hline $\begin{array}{l}\text { 교사의 } \\
\text { 니즈와 } \\
\text { 어려움 } \\
\text { 순간 } \\
\text { (pain } \\
\text { point) }\end{array}$ & \multicolumn{5}{|c|}{$\begin{array}{l}\text { - 각 교과 특성과 연계한 진로교육을 진행할 수 있는 세분화/전문화된 연수 및 학습자료 부족 } \\
\text { - 학사운영 과정 내, 교과 진도 및 학승 내용에 연결되는 진로교육 프로그램을 진행하고 싶음 } \\
\text { - 교과 주요 역량과 각 학생 진로 방향을 연결하는 개별 맞춤 진로교육 활동 구성하고 싶음 } \\
\text { - 한정적 수업 시간과 공간(교실)에서 일반교사가 다수의 학생과 효과적으로 진행할 수 있는 } \\
\text { 단계적 교육 프로그램 운영 시스템이 필요함 } \\
\text { - 학생 주도적 참여/창의적 탐구/문제해결활동 중심의 진로 연계 교과교육 방안 연수 필요함 } \\
\text { - 새로운 관점 제시, 상호 의견 교류 위해 진로탐색 활동에 대한 교사의 직접적 선 경험이 } \\
\text { 필요함 }\end{array}$} \\
\hline 구분 & 교육 진행 전 & & 교육활동 진행 & & 교육활동 진행 후 \\
\hline $\begin{array}{l}\text { 사용자 } \\
\text { 여정 }\end{array}$ & 교육 정보 습득 & $\begin{array}{c}\text { 교과 연계 } \\
\text { 진로교육 안내 }\end{array}$ & 프로그램 진행 & $\begin{array}{l}\text { 평가 및 개별 } \\
\text { 피드백 제공 }\end{array}$ & $\begin{array}{c}\text { 수업 평가 및 후속 } \\
\text { 수업 준비 }\end{array}$ \\
\hline $\begin{array}{l}\text { 터치 } \\
\text { 포인트 }\end{array}$ & $\begin{array}{l}\text {-배포/연수 } \\
\text { 자료 } \\
\text {-웹 리서치 } \\
\text {-교과서 }\end{array}$ & $\begin{array}{l}\text {-교실 환경/시설 } \\
\text {-참여 학생 반응 }\end{array}$ & $\begin{array}{l}\text {-학습 자료/교구 } \\
\text {-학생과의 교류 }\end{array}$ & $\begin{array}{l}\text {-활동 결과물 } \\
\text {-개별 학생 } \\
\text { 반응 }\end{array}$ & $\begin{array}{l}\text {-교육평가 자료 } \\
\text {-교사 교류 } \\
\text {-웹 리서치 }\end{array}$ \\
\hline 감정 & $\begin{array}{l}\text { 전문적인 정보 } \\
\text { 접근의 어려움, } \\
\text { 수업 활동 } \\
\text { 구성의 막막함 }\end{array}$ & $\begin{array}{c}\text { 신규 활동 진행 } \\
\text { 및 교과 수업 } \\
\text { 확장에 대한 } \\
\text { 기대감 } \\
\end{array}$ & $\begin{array}{l}\text { 비전문 프로그램 } \\
\text { 진행의 어색함, } \\
\text { 활동 결과 및 } \\
\text { 효과의 불안함 }\end{array}$ & $\begin{array}{c}\text { 진로연계 } \\
\text { 프로젝트 활동 } \\
\text { 결과물에 대한 } \\
\text { 실망감 } \\
\end{array}$ & $\begin{array}{c}\text { 수업 효과에 대한 } \\
\text { 좌절감, 연계 수업 } \\
\text { 구성의 어려움 }\end{array}$ \\
\hline 문제점 & $\begin{array}{l}\text { 교과별 학습역량 } \\
\text { 및 교육과정 } \\
\text { 특성과 연계한 } \\
\text { 교육정보 제공 }\end{array}$ & $\begin{array}{l}\text { 다양한 교과 } \\
\text { 수업 환경에 } \\
\text { 활용이 가능한 } \\
\text { 자료 필요 }\end{array}$ & $\begin{array}{l}\text { 진로교육 경험 } \\
\text { 확대를 위한 } \\
\text { 실제적 내용의 } \\
\text { 연수 경험 필요 }\end{array}$ & $\begin{array}{l}\text { 실효성이 } \\
\text { 검증된 확장적 } \\
\text { 교육 프로그램 } \\
\text { 제공 }\end{array}$ & $\begin{array}{l}\text { 전문적 평가도구 } \\
\text { 마련 및 단계적 } \\
\text { 과정의 교육 방안 } \\
\text { 제공 필요 }\end{array}$ \\
\hline
\end{tabular}

위와 같은 교과연계 진로교육 교사 여정 지도 작성 및 분석을 통해, 본 연구자들은 일반교사들이 교과연계 진로교육에 대해 충분하게 인지하고 있음에도 불구하고, 교과 과정에 적절히 연계되면서도 실효성 높은 진로교육을 실행하기 어려운 주요 원인들을 
발견할 수 있었다. 즉 교사들의 니즈에도 불구하고 현재의 진로교육 교사 연수는 진로교육에 대한 포괄적/일반적인 내용 전달 위주로 구성되어 있었다. 또, 실제 학교 교육 현장의 상황 및 교사들 스스로 교과와 연계한 진로교육을 구성해 본 경험의 부족으로 인해 수업 운영의 어려움 및 한계점이 발생하고 있음을 확인할 수 있었다. 무엇보다 교과연계 진로교육의 취지는 학생들이 다양한 삶의 가치 및 진로에 대한 이해를 교과 내에서 찾을 수 있도록 하는 것으로, 개별 학생들의 교과 연계 진로를 지도하기 위해서는 교사-학생, 학생-학생 간의 양방향적인 활동으로 구성할 필요가 있으나, 교과연계 진로교육을 위한 교수 학습 구성 및 평가 매뉴얼 등의 부족은 교과연계 진로교육의 실효성을 떨어뜨리는 결과를 낳고 있었다. 따라서, 교과 영역별 교육 요소 및 특성을 고려한 세분화된 진로교육 연수 자료와 및 실제 교육 환경 및 수업에 적용할 수 있는 교수학습 프로그램 제공이 필요하다. 또한, 교과 역량과 융합 가능한 분야들이 더욱 복합적으로 발전하고 있는 사회적 상황, 다양한 학생들의 가치관 등을 만족시키기 위해, 단계적 내용 확장 및 양방향적 소통이 가능한 프로젝트형 수업 설계의 방안 제시가 필요한 것으로 분석되었다.

\section{4. 디자인 사고 프로세스 적용 교과 연계 진로교육 교사 연수 프로그램 설계}

본 연구는 이러한 문제점을 대처하기 위한 방안으로서 디자인적 사고(design thinking)에 기반한 교사 연수 프로그램을 설계하였다. 먼저, 본 교사 연수 프로그램의 주요 학습 목적 및 방법을 1) 융합적 학습 프로젝트 수행을 통한 인성과 인지의 균형적 발달, 2) 자율적 학습환경 제공을 통한 학습자 내외적 동기유발, 3) 경험 기반 아이디어 습득 및 창의적 사고 적용 훈련, 4) 협업/논의를 통한 문제해결 과정, 5) 다양한 표현 언어의 체득으로 설정하였다. 교사 연수 프로그램 설계의 방법론으로 적용할 디자인 사고의 핵심 역량 및 평가 항목은 스탠포드 대학교의 디자인스쿨(D-School)이 제시한 8가지 역량 내용을 근거로 삼았다.

각 항목들과 연결되는 2015 개정 교육과정의 핵심 역량 내용을 1) Navigate ambiguity 폭넓은 기초지식/기술/경험의 융합 활용, 2) Learn from others - 타인에 대한 공감적 이해와 수용, 3) Synthesize information - 다양한 영역 정보의 종합적 이해 및 활용, 4) Experiment rapidly - 새로운 것을 창출하는 창의적 사고, 5) Move between concrete \& abstract - 목표 및 원리 정의의 추상화와 세부사항 마련의 구체화를 넘나들며 관리, 6) Build \& craft intentionally - 의도에 따른 계획적 구축 및 정교한 제작, 7) Communicate deliberately 생각/감정의 효과적 표현과 타인 경청/존중, 8) Design your design work - 문제를 합리적으로 해결하는 메타역량으로 정리하였다. 이러한 기준 마련은 개발 프로그램의 적합성을 높이고자 한 것이다. 이러한 종합적 적용을 통해 문제해결 과정을 통해 체득할 수 있는 역량에 중점을 둔 'In-프로그램 구조'의 연수 프로그램을 [표 3]과 같이 구성하였다.

In-프로그램 구조는 디자인 사고 프로세스가 적용된 전체 연수 프로그램의 구조 안에서 프로그램 세부 활동인 교과연계 수업모형 설계에 디자인 사고 프로세스를 적용하는 이중적 구조를 구성한 것이다. 연수 참여 교사들은 디자인 사고 프로세스가 적용된 전체 연수 프로그램의 흐름을 경험하며 확산적 사고와 창의적 발상, 주도적 태도, 의사소통과 협력, 문제해결 과정 및 결정 등을 중심으로 한 진로교육 역량을 체득할 수 있었다. 나아가 수업 모형을 설계해 보는 'In-프로그램'을 통해, 교사들은 학생들의 학습 활동 방법으로 제시할 디자인 사고 프로세스의 과정 및 결과를 직접 경험하고, 수업 방안을 
The Direction of Subjects-Related Career Education by Developing Teachers' Training Program Reflecting Journey Map: Focused on the Application of Design Thinking Process

스스로 보완 및 발전시켜 나갈 수 있었다. 이러한 구조는 참여 교사들이 자신의 교과 학습 내용을 기반으로 교과연계 학습 내용과 연계한 진로교육 활동의 시행 방안을 발견하게 한 것이다. 또한, 연수에 참여한 다양한 교과 교사들이 문제해결 능력 및 토의를 통한 수평적 사고 역량을 강화함으로써 진로교육의 다양한 가능성과 접근법을 교사 스스로 탐구할 수 있는 근간을 마련하고자 하였다.

[표 3] 디자인 사고 프로세스의'In-프로그램’교과 연계 진로교육 교사연수 프로그램

[Table 3] Subjects-Related Career Education Teacher Training Program of ' In-program Structure' based on the Design Thinking Process

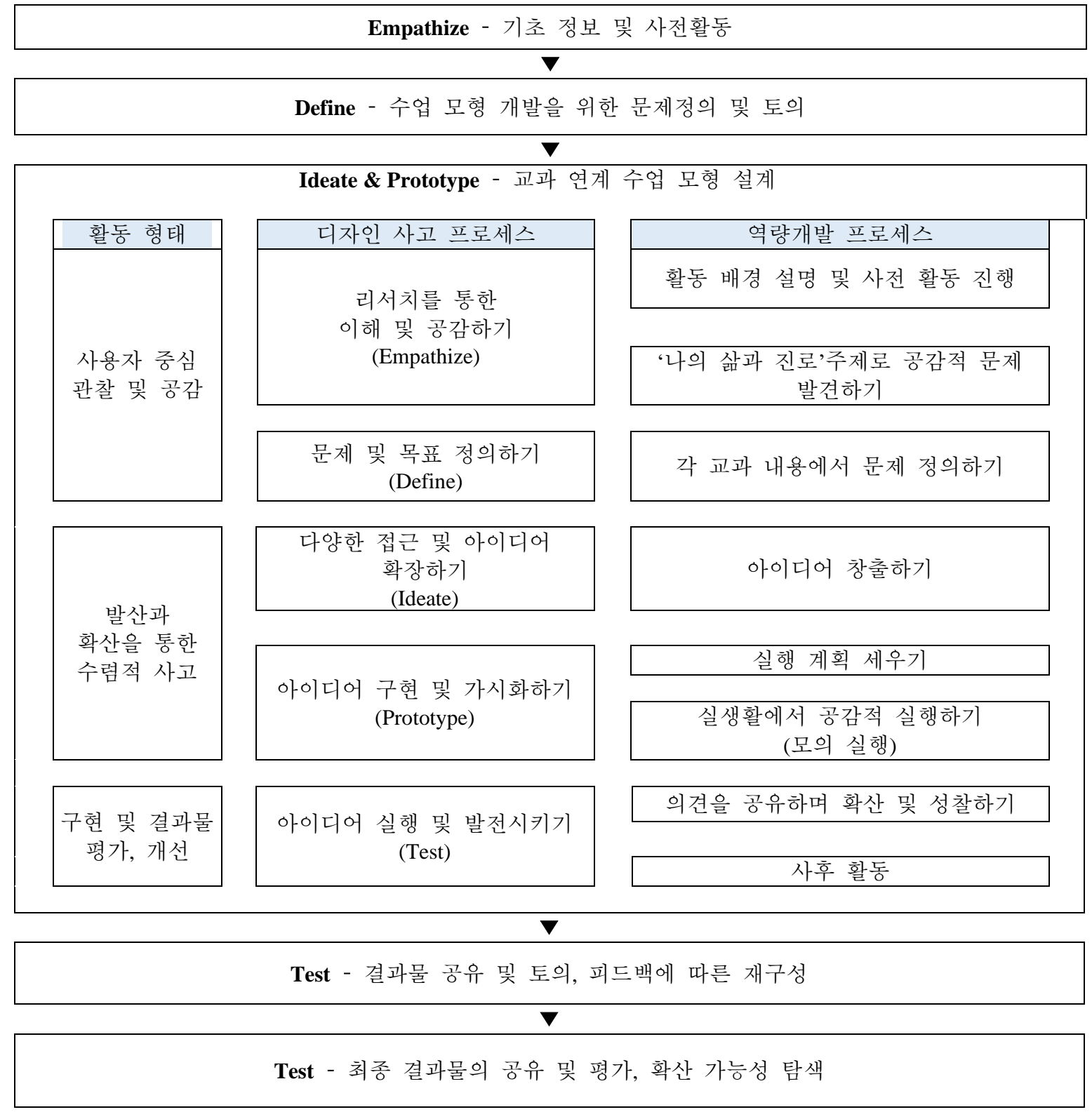

\section{5. 결론}

본 연구는 중등학교 교사의 교과연계 진로교육 역량 강화를 목적으로 현직 교사들이 
경험을 통해 인식하고 있는 진로교육 연수의 필요성과 세부적인 요구 수준을 확인하고, 다양한 교과에 적용 및 확산이 가능한 교수학습 방법론 제시의 필요성을 확인하는 것을 목적으로 하였다. 이를 위해 일반교사 대상 진로교육 연수의 필요성 고찰 및 해결 방안 발견을 위한 방법으로 여정 지도의 작성 및 분석을 진행하고, 이를 바탕으로 디자인 사고 프로세스 적용 연수 프로그램을 개발하여 실제 교과연계 진로 수업에 적용할 수 있는 실효성 높은 수업 모형의 틀을 제시하였다.

연구의 결과 일반교사들은 교과연계 진로교육의 필요성에 대한 요구가 높으나 이를 뒷받침할 수 있는 연수 프로그램의 부족과 교수학습 구성 및 평가 매뉴얼 등의 부족으로 교육의 실효성이 떨어진다고 보고하였다. 이러한 교사들의 요구를 반영하여 본 연구에서는 청소년 교과연계 진로교육 역량을 반영한 디자인 사고 적용 연수 프로그램을 개발하는 전 과정에서 교사들의 의견을 반영하였다. 그리고 일반교사가 교과연계 진로교육을 할 수 있는 교수학습 구조로서 디자인 사고 프로세스를 구상하도록 하여 교사 스스로 창의적 문제해결 과정을 경험하고, 맥락적 이해를 통해 진로교육 관련 역량을 향상시킬 수 있도록 하였다. 이를 통해 참여교사들은 교사들의 전공 교과 학습내용을 진로교육 활동으로 확장시킬 수 있는 경험을 할 수 있도록 하였다.

본 연구는 현 학교 교육 실정 및 다양한 교과 전문가들의 요구를 반영하여 중등학교 일반교사를 위한 교과 연계 진로교육 연수 프로그램을 개발하고, 교과 특성에 따라 다양한 적용이 가능한 교수학습 틀을 제시하였다는 점에 의의가 있다. 무엇보다 다양한 교사들이 직접 참여하는 프로그램 개발과 교사들 스스로 전문성 발현을 높이는 동시에, 디자인 사고 프로세스를 체득할 수 있는 'In-프로그램' 구조의 연수 프로그램을 구상하였다는 측면에서 다른 연구와의 차별성을 갖는다. 또한 'In-프로그램' 구조는 연구의 대상자가 연수 프로그램을 설계하는 역할을 동시에 하는 것으로, 연수 프로그램의 적용과 개발 단계에서 대상자인 교사들의 검증 및 의견을 반영하여 디자인 사고 프로세스를 통한 교과연계 진로 교육의 높은 가능성과 시사점을 발견할 수 있었다.

반면 본 연구는 연수 프로그램 개발에 초점을 맞춰, 프로그램 시행에 따른 교사들의 전/후 인식 및 역량 변화나 수업모형적용에 따른 학습 효과에 대한 비교 측정은 진행하지 않았다. 따라서 추후 연구에서는 개발된 프로그램을 실제적 규모의 교사 연수에서 적용하고, 그 효과를 전후 비교 등을 통해 구체적으로 분석하여 프로그램 및 수업 모형의 효과성 및 확장 방안을 모색할 필요가 있다.

\section{References}

[1] W. W. Huh, J. G. Cho, A Study on the Direction career Education in the Fourth Industrial Revolution, Asia-Pacific Journal of Multimedia Services Convergent with Art, Humanities, and Sociology, (2018), Vol.8, No.9, pp.505-512, DOI: 10.35873/ajmahs.2018.8.9.050

[2] J. E. Noh, M. N. Jung, A study on the change patterns of career identity and its influence factors in adolescents, Journal of Future Oriented Youth Society, (2017), Vol.14, No.3, pp.51-68.

[3] S. G. Han, M. K. Kim, Y. J. Ahn, J. S. Ahn, National career education center operation support 1, career education status survey: Elementary and secondary career education status survey, Ministry of Education \& Korea Research Institute for Vocational Education and Training, Research Materia, pp.19-41, (2019), https://www.career.go.kr/cnet/front/web/courseEdu/courseEduIndicator2019.do\#

[4] M. Jena, K. So, An analysis of implementation of career education in middle school: Focusing on Excellent Schools in Curriculum, The Journal of Career Education Research, (2016), Vol.29, No.4, pp.135-155, UCI: G704- 
The Direction of Subjects-Related Career Education by Developing Teachers' Training Program Reflecting Journey Map: Focused on the Application of Design Thinking Process

001285.2016.29.4.003

[5] E. J. Kim, An exploration of a direction of integrated subject career education in elementary practical arts education, The Journal of Learner-Centered Curriculum and Instruction, (2018), Vol.18, No.20, pp.1211-1233, DOI: $10.22251 /$ jlcci.2018.18.20.1211

[6] W. S. Seo, A comparative study on career education in elementary schools in Korea and Japan, Journal of Korean Practical Arts Education, (2018), Vol.24, No.1, pp.195-218, DOI: 10.29113/skpaer.2018.24.1.195

[7] N. Kim, H. Lee, Y. Lee, Y. K. Jeong, Y. Cho, Analysis of experiences and effects of high school teachers' subjectsrelated career education classes using grounded theory, The Journal of Career Education Research, (2018), Vol.31, No.2, pp.27-50, DOI: 10.32341/JCER.2018.06.31.2.27

[8] J. S. Kim, B. K. Cho, M. H. Lee, S. B. Kim, J. H. Kim, Curriculum-related career education current status analysis and development plan exploration, Research Report RRC 2018-1, Korea Institute of Curriculum \& Evaluation, pp.152, (2018), https://scienceon.kisti.re.kr/srch/selectPORSrchReport.do?cn=TRKO201900002181

[9] S. K. Lee, Exploring the educational implications and practical action plans of social emotional learning to improve adolescents' subjective well-being, The Journal of Learner-Centered Curriculum and Instruction, (2017), Vol.17, No.19, pp.585-609, DOI: 10.22251/jlcci.2017.17.19.585

[10] C. Holmgren, J. From, A. Olofsson, H. Karlsson, K. Snyder, U. Sundtröm, Entrepreneurship Education: Salvation or Damnation?, Journal of Entrepreneurship Education, (2005), Vol.8, pp.7-19.

[11] D. Y. Moon, Development of performance assessment rubric for invention problem solving based on design thinking, Journal of Korean Practical Arts Education, (2018), Vol.24, No.4, pp.39-54, DOI: $10.29113 /$ skpaer.2018.24.4.039

[12] S. J. Han, A study on learning effects using design thinking process, Asia-pacific Journal of Multimedia Services Convergent with Art, Humanities, and Sociology, (2019), Vol.9, No.7, pp.271-286, DOI: 10.35873/ajmahs.2019.9.7.025

[13] H. Jung, C. Kim, A Study on the Entrepreneurship Education Framework for Youth based on Design Thinking, Journal of the Korean Entrepreneurship Society, (2018), Vol.13, No.1, pp.175-200, DOI: $10.24878 /$ tkes.2018.13.1.175

[14] https://dschool.stanford.edu/, Oct 28 (2021)

[15] E. J. Oh, Case Study of the Effects of Study Hours In the Design Thinking Classes, Asia-pacific Journal of Multimedia Services Convergent with Art, Humanities, and Sociology, (2019), Vol.9, No.12, pp.225-234, DOI: 10.35873/ajmahs.2019.9.12.022

[16] E. Chon, H. Jung, Development and Effect Analysis of College Students' Career Curriculum Based on Career Constructivism and Design Thinking, The Journal of Humanities and Social science, (2019), Vol.10, No.6, pp.767782, DOI: 10.22143/HSS21.10.6.55

[17] E. J. Kim, E. C. Jung, The Model of Comprehensive Journey Map for the Visualization Analysis of Information about User Experiences, Journal of Korea Design Forum, (2015), No.46, pp.389-399, DOI: $10.21326 / \mathrm{ksdt} .2015 . .46 .035$

[18] J. Lee, S. Ryu, M. Lee, A Study on Enhancing Museum Visitors' Experiences -Focusing on the Analysis of the Visitor Journey Map of National Modern Museum of Contemporary Art, Korea-, Journal of Communication Design, (2021), Vol.74, pp.123-134, DOI : 10.25111/jcd.2021.74.10

[19] E. J. Lee, A study on the development of a spatial design education program with enhanced visual communication elements: with a focus on a customer journey map, Hanyang University, Master's thesis, pp.1-135, (2020)

[20] Service Design Toolkit, Korea Institute of Design Promotion, pp.1-64, (2014), https://www.slideshare.net/sdnight/ss35612373 